\title{
Health Pedagogy and Sport: Attitudes and Practices of Gymnastics Coaches
}

\author{
Silvia Coppola ${ }^{1}$ and Rodolfo Vastola ${ }^{1}$ \\ Department of Human Sciences, Philosophy \& Education, University of Salerno, Salerno 84084, Italy
}

\begin{abstract}
Gymnasts are exposed to intense training, frequent competitions, controlled diets and high levels of psychological distress in youth age. These aspects can negatively affect athletic performance and have health consequences. Accordingly, if the coaches do not possess adequate knowledge and specific multi-disciplinary skills related to sports practice and health pedagogy, young athletes can be exposed to different health risks. The aim of this study is to investigate the knowledge and attitudes of coaches and identify any education needs to enhance or preserve the gymnasts' well-being. The sample is represented by 98 Italian rhythmic gymnastics coaches of different levels. The data were obtained by using structured and anonymous questionnaires with open and closed answers administered through interview. The aspects examined are related to nutrition, food supplements, overtraining syndrome, educational topics, gymnasts' hassles and trainings needs of coaches. Critical aspects that emerge from this study show the need for specific scientific training and support for coaches. This objective can be achieved by providing constant technical and scientific support, in order to make the coaches fully aware of their educational, pedagogical and long-term health responsibilities of their athletes.
\end{abstract}

Key words: Gymnastics, training, education, coaches, health pedagogy.

\section{Introduction}

The main environmental components that can alter optimal growth in top-level sports are nutritional status, stress and intense physical activity [1]. High-level gymnastics is one of the few sports disciplines in which the three potential risk factors act simultaneously. The gymnasts, in fact, are particularly sensitive to growth alterations, because they are exposed to intense training, low calorie diet, and high levels of psychological stress [2-4]. Top-level gymnasts' trainings are held on average four times a week for three hours; increasing age and level workouts become daily and last for more than four hours in order to implement the provisions of the competition programs and achieve the performance objectives required by programming agonistic. The athletes of international level also train two times a day [2]. Intense training and frequent agonistic competitions, combined with low levels of nutrition

Corresponding author: Silvia Coppola, Ph.D., Research Fellow, research fields: Methods and Didactics of Physical Activities and Sport. and unhealthy eating habits, can adversely affect sports performance and have long-term consequences $[1,5$, 6]. This phenomenon is also accentuated by the role that makes the aesthetic component in this discipline [7]. Menarche's delay and eating disorders are common in gymnasts, which are considered a high-risk group of malnutrition $[8,9]$.

It is evident, therefore, that if sports technicians do not have the specific and implicit multidisciplinary skills and competences of the practice of sports discipline, young athletes may be exposed to various health risks.

In Italy, this sport has been widespread and growing in recent years, ranking the world rankings and recording a growing number of gymnasts; in 2017 gymnastics is the third most popular sport for girls [10].

The attention of the international scientific community to cross-disciplinary aspects of sports practice has steadily increased in recent years [11, 12]. The long-term health protection and didactic-educational aspects, pedagogical health in 
sport are the topics that most researchers have been interested in lately $[13,14]$. It is now recognized that sports organizations can be an important setting for implementing health promotion strategies that cover practices, disseminate health messages and create health-promoting environments and acquire positive growth attitudes for the formation of the person [15, 16]. The purpose of this work is to investigate the knowledge and attitudes of sports technicians in this discipline and to identify any training needs to improve and preserve the well-being of gymnasts.

\section{Objective}

The aim of the study is to investigate the attitudes and competences in gymnastics coaches, referring to issues related to health promotion and health pedagogy.

\section{Methods}

This survey is an observational study. They were recognized attitudes, knowledge and training needs of the coaches in the sports sector, especially the rhythmic gymnastics field.

The study is on national level and the sample consists of 98 coaches.

The aspects investigated include the analysis of both methodological and didactic knowledge and attitudes.

The data were obtained with structured anonymous questionnaires, conducted through telephone interviews.

\subsection{Questionnaire}

The telephone interview was completely structured, that is, conducted based on a standardized questionnaire whose questions were put to the interview as well as formulated. This is to obtain comparable information.

The questionnaire consists of the following sections:

- level of coaching qualification, number and technical level of trained gymnasts;

- opinions on the involvement of coaches in health promotion activities;
- topics discussed with athletes, in addition to technical sports, during training sessions;

- knowledge of principles of healthy nutrition (requirements, use of dietary supplements, food deficiencies);

- advice to athletes about nutrition;

- any problems complained of gymnastics (dizziness, cramping, menstrual cycle alteration, back pain, etc.);

- knowledge about overtime training syndrome;

- knowledge about the Life Skills Educational Model;

- training needs expressed by coaches to contribute to a health pedagogy for athletes.

Care was taken to formulate questions with particular regard to clarity and simplicity of language.

It has also been attempted to minimize the possibility of influencing the respondent's response.

Finally, during the drafting phase, the length of the questionnaire was also evaluated, which, if excessive, may be a definitive interruption factor of the interview. The expected questions are 23 and provide both open and closed answers.

\subsection{Conduct of Interviews}

Interviews were conducted by a single interviewer and they have been carried out over two months.

\subsection{Data Archiving and Processing}

Data collected on paper questionnaires, after careful testing, were stored on magnetic media by providing a database for registration in the MS Access program.

Data processing was performed using MS Excel and STATA programs.

\section{Results and Discussion}

\subsection{General Data}

Table 1 shows the distribution of the sample of coaches interviewed for each region and the number of gymnasts in the same territorial stratifications.

In absolute numbers, the regions where more coaches 
Table 1 Sample on a national level.

\begin{tabular}{lll}
\hline Regions & Number of athletes & Number of coaches interviewed \\
\hline Abruzzo & 2,215 & 5 \\
Basilicata & 346 & 1 \\
Calabria & 1,073 & 2 \\
Campania & 4,849 & 5 \\
Emilia romagna & 5,905 & 10 \\
Friuli-venezia-giulia & 4,299 & 2 \\
Lazio & 6,123 & 8 \\
Liguria & 3,318 & 6 \\
Lombardy & 10,638 & 11 \\
Marche & 4,510 & 5 \\
Piedmont & 5,301 & 12 \\
Apulia & 2,762 & 4 \\
Sardinia & 2,087 & 2 \\
Sicily & 2,602 & 3 \\
Tuscany & 4,596 & 6 \\
Umbria & 2,909 & 2 \\
Aosta valley & 256 & 1 \\
Veneto & 6,898 & 13 \\
Total & $72,943 *$ & 98 \\
\hline
\end{tabular}

* Number of athletes in all gymnastics areas at national level [10].

Table 2 Age range of the gymnasts reported by respondents' coaches.

\begin{tabular}{lll}
\hline & Minimum age values & Maximum age values \\
\hline from & 3 & 12 \\
to & 8 & 29 \\
\hline
\end{tabular}

were interviewed are Veneto (13 coaches interviewed), Piedmont (12), Lombardy (11) and Emilia Romagna (10). The regions with the lowest number of coaches are Basilicata (1), Aosta Valley (1), Calabria, Sardinia, Umbria and Friuli Venezia Giulia (2).

Regarding the coaches certification, the subjects monitored are mainly "National Coaches-III Level" (70 coaches, equal to $71.4 \%$ ), followed by "Regional Coaches-Level II" (23, 23.5\%), “International Coaches - IV Level" (4, equal to 4.1\%) and a single "Basic Coaches-Level I".

All the interviewed coaches are female and train girls. The training population of the coaches surveyed in the present study was about 3,700 gymnasts. The large number of gymnasts trained by coaches does not seem related to the level of qualification held by the coach, as verified by ANOVA statistical test $(p>0.05)$.

The age of gymnastics trained by the coaches achieved by the study was very variable, in total, from three to 29 years (Table 2), and this feature is not correlated with the level of the trainer. The time commitment in weekly workouts is also very different among the interviewees: it can range from four to 40 hours/week. In this case, as plausible, average values differ by category, in particular, they are very high for "Level IV Coaches" (26.3 \pm 9.2 hours/week) compared to "Level III Coaches" (14, $8 \pm 5.1$ hours/week) and "Level II Coaches" (13.6 \pm 5.4 hours/week) (statistically significant differences also in this case at the ANOVA test, $p<0.01$ ). In total, $86 \%$ of respondents participated with their athletes in competitions and championships; this frequency is significantly different between the coaches' levels "Level IV" (100\%) and "Level III" (97\%) vs. "Level II" $(53 \%)(8 p<0.01$, exact Fischer test). Regarding the type of races, $57 \%$ participate in both agonistic and 
promotional competitions, $33 \%$ only participate in agonistic races, and $9 \%$ only participate in promotional competitions.

\subsection{Knowledge, Experience and Opinions on Health Promotion Thematics}

Regarding the involvement of coaches in health promotion activities only about 5\% reported that it is not appropriate. Concerning practicality, 23\% replied that it is not workable. To the question "other opinions about it" responded in 17, 5 of them have expressed the need for training in areas of health promotion, 7 have stated that there is not enough time and 4 have expressed very favorable opinions about the that topic. It is interesting to note that those who declared non-viable practice have on average more abundant training sessions (21 hours) than those who responded positively to practicability ( 15 hours) $(p<0.05$ t Test 2 queues).

Table 3 shows sharing rates with respect to the contents of any health education/health promotion activities for the four categories of trainees surveyed. Almost all of the coaches of different levels indicate food as one of the educational topics of choice, followed by the risk of injuries in sports practice. Doping is indicated only by two national technicians $(50 \%)$ and less than half of the lowest technicians. There are very few percentages of coaches sharing about the opportunity to conduct educational activities focusing on volunteering behaviours, such as smoking (no national coach, about $30 \%$ of others), alcoholism ( $25 \%$ of national coaches, and $10 \%$ of others), psychotropic substances prohibited (about $20 \%$ of all coaches). The information just mentioned is an interesting and disillusioning profile of coaches in their potential role as educators and health promoters. Surprisingly the apparent low interest of the doping coaches is quite unexpected, as well as a bit daunting that other emerging lifestyle issues, such as teenagers' widespread risks, are not considered.

As expected, food is one of the topics of interest warmest among gymnasts, for notes of body image implications of specialty and technical and artistic performance. As shown in Table 4, the question of feeding more than $88 \%$ of respondents answered that they gave advice, $10 \%$ prescribed diets, $48 \%$ advised to consult a physician or a nutritionist and $82 \%$ spoke to her with her parents. An interesting aspect, as shown in Table 4 , is that almost all the coaches who gave advice, prescribed diets and talked with their parents stated that they needed information.

Additionally, six of them have questionable opinions about food ("weigh them every week", "less eat it is better", etc.). An important fact is that these six coaches have given advice, prescribed diets, and talked with their parents.

Table 3 Educational topics which deserve attention divided by the coach level.

\begin{tabular}{lllll}
\hline Topics & C. I level & $\begin{array}{l}\text { C. II level } \\
(1)\end{array}$ & $\begin{array}{l}\text { C. III level } \\
(70)\end{array}$ & $\begin{array}{l}\text { C. IV level } \\
(4)\end{array}$ \\
\hline Doping and dietary suppl. & 0 & $8(35 \%)$ & $28(40 \%)$ & $2(50 \%)$ \\
Psychotropic substances & 1 & $5(22 \%)$ & $10(14 \%)$ & $1(25 \%)$ \\
Food regimes & 1 & $23(100 \%)$ & $66(94 \%)$ & $4(100 \%)$ \\
Risk of injuries & 0 & $23(100 \%)$ & $58(83 \%)$ & $3(75 \%)$ \\
Smoking & 0 & $7(30 \%)$ & $20(29 \%)$ & 0 \\
Alcoholism & 0 & $2(9 \%)$ & $8(12 \%)$ & $1(25 \%)$ \\
\hline
\end{tabular}

Table 4 Commitment of nutrition coaches of female athletes (related behaviors and training needs).

\begin{tabular}{lll}
\hline & & Need for information \\
\hline Coaches who give food advice & 87 & 79 \\
Coaches who prescribe diets & 10 & 10 \\
Coaches who advise a nutritionist & 47 & 46 \\
Coaches who talk about diet with gymnastics parents & 80 & 75 \\
\hline
\end{tabular}


Another uncomfortable aspect, given the level of active interventions among adolescents and their families on dietetic regimens, is related to their knowledge of caloric needs of adolescents and, in particular, those who practice sports (Table 5); 63 out of the 98 trainees surveyed believe that the caloric requirement is approximately $1,100 \mathrm{kcal}, 5$ believe that it is about $800 \mathrm{kcal}$ and only 30 of them have responded correctly [17].

To investigate the level of interaction between coaches and their athletes with regard to physical and psycho-social well-being, and confidence levels that may be predictive of a greater/lesser success of training/education in sporting setting, respondents were asked if they are usually faced with other issues in training: $87 \%$ of respondents said they were dealing with issues such as school, family or friends during their workouts; a small percentage also spoke of other issues such as politics, education, respect for rules and well-being.

The data in Table 6 show a low level of knowledge by the coaches on the correct use of dietary supplements [18]. This finding is borne out by further responses to the request for a definition of a dietary supplement; over $60 \%$ of respondents expressed a very poor level of information and synthesized summarily the explanation required by the term "diet aid".

There has been requested information on any pain manifested by gymnasts (Table 7). Obviously, as children and adolescents, the presence of these troubles is not encouraging. Additionally, the question "More about the subject?" was answered by 15 , of which 5 pointed out the presence of menstrual changes and, in particular, the delay of menarche in these athletes. Other coaches reported joint, muscular and psychological problems.

The information collected on knowledge of the overactive training syndrome is not comforting (Table 8), as in addition to the fact that almost half of the respondents admitted they did not know it, those who made themselves informed had given very trivial and vague explanations ("too much training": 14 out of 46), "I do not know": 12 out of 46) [19].

Confirming that the information and interests on the methodologies and contents attributable to the pedagogy of health are actually lacking in the trainers

Table 5 Trainer's knowledge about average caloric needs of teenage gymnasts.

\begin{tabular}{ll}
\hline The caloric needs of teenage gymnasts are about: & Affirmative responses \\
\hline $1.100 \mathrm{kcal}$ & $64 \%$ \\
$2.000 \mathrm{kcal}$ & $30 \%$ \\
$800 \mathrm{kcal}$ & $5 \%$ \\
\hline
\end{tabular}

Table 6 Knowledge on food supplements.

\begin{tabular}{ll}
\hline A dietary supplement is necessary & Affirmative responses \\
\hline For a specific deficiency & $70 \%$ \\
For a period of growth & $50 \%$ \\
To increase confidence in athletes & $7 \%$ \\
To facilitate training session & $39 \%$ \\
\hline
\end{tabular}

Table 7 Pain complained by the gymnasts as reported by the coaches.

\begin{tabular}{ll}
\hline Pain & $\%$ of coaches reporting them \\
\hline Dizziness & $21 \%$ \\
Weakness & $51 \%$ \\
Cramps & $25 \%$ \\
Back pain & $76 \%$ \\
Muscle strain & $40 \%$ \\
Menstrual cycle irregularities & $41 \%$ \\
\hline
\end{tabular}


Table 8 Knowledge of overtraining syndrome.

\begin{tabular}{lll}
\hline Knowledge of overtraining syndrome & Affirmative responses & Negative answers \\
\hline & $52 \%$ & $47 \%$ \\
\hline
\end{tabular}

Table 9 Knowledge of the Life Skills Educational Model.

\begin{tabular}{lll}
\hline Knowledge of the Life Skills Educational Model & Affirmative responses & Negative answers \\
\hline
\end{tabular}

Table 10 Opinion of coaches on the practice of gymnastics on a competitive level.

\begin{tabular}{lll}
\hline $\begin{array}{l}\text { If you had a daughter, would you practice her rhythmic } \\
\text { gymnastics at a competitive level? }\end{array}$ & Affirmative responses & Negative answers \\
\hline
\end{tabular}

Table 11 Trainers' opinions on the interaction between educational institutions (schools, associations, etc.) and sports associations.

\begin{tabular}{llll}
\hline $\begin{array}{l}\text { Do you think the interaction between educational } \\
\text { institutions and sports is appropriate? }\end{array}$ & $\begin{array}{l}\text { Affirmative } \\
\text { responses }\end{array}$ & Negative answers & No reply \\
\hline & $90 \%$ & $5 \%$ & $4 \%$ \\
\hline Do you feel it is workable? & $\begin{array}{l}\text { Affirmative } \\
\text { responses }\end{array}$ & Negative answers & No reply \\
\hline & $72 \%$ & $8 \%$ & $19 \%$ \\
\hline
\end{tabular}

Table 12 Training requirements reported by coaches.

\begin{tabular}{llll}
\hline $\begin{array}{l}\text { Do you think you need information to contribute } \\
\text { to the health of your gymnasts? }\end{array}$ & $\begin{array}{l}\text { Affirmative } \\
\text { responses }\end{array}$ & Negative answers & $\begin{array}{l}\text { Unsatisfactory answers } \\
\text { (I do not know) }\end{array}$ \\
\hline & $90 \%$ & $5 \%$ & $4 \%$ \\
\hline
\end{tabular}

is the data collected on the knowledge of the Life Skills Education model [20,21], virtually unknown to all respondents (only 1 in 98 says he has heard of it) (Table 9).

To assess the level of concern about any negative outcomes or fears of unhealthy experiences associated with the practice of this sport, the interviewed opinions on practicing gymnastics were asked for. This figure also needs to be supplemented with the responses given by the coaches: $43 \%$ of those who gave an affirmative answer then specified some limitations related to the risks associated with the preparation of the technicians ( 25 of them) and training loads ( 6 of the favorable).

Regarding the personal experience of health issues related to the practice of this sport, information was requested from high-level ex-gymnasts, $32 \%$. In particular, they were asked if they had any problems (health or otherwise) that they felt were related to their gymnastics career and $90 \%$ of them answered affirmatively. Most have reported back and joint pains.

Surprisingly, as compared to the question about experience and knowledge, almost all the interviewees (90\%) expressed a positive opinion on the possibility of interaction between sports associations and other institutions and actors involved in the education/growth process gymnasts (e.g. parents, schools, associations, etc.) (Table 11). When asked about the practicability of the intervention, this percentage decreases, bringing various reasons. Most of the interviewees (56\%) express a unanimous opinion about the school which, in their view, does not consider sport as positive, particularly at a competitive level, so it is difficult to collaborate.

In conclusion, a question was asked about the need for information to contribute to the health of gymnasts. As shown in Table 12, it is evident that the training requirements of coaches are very high $(90 \%)$ as self-reported by them. 


\section{Conclusions}

Based on the results obtained, it can be stated that the method of investigation that was employed was effective. Telephone interviews, in fact, had a very high response rate and respondents replied positively. A positive aspect of using the interview, linked to the purposes of the survey, was the extemporaneous. In fact, in evaluating the actual knowledge and attitudes, it was crucial to determine the spontaneity and level of responsiveness. A questionnaire sent by e-mail or online would have distorted the determination of these features, not only because of the longer reflection time but also the suggestions from documentation from other sources. The sample was appropriate for a "strategic" evaluation of results and to make appropriate conclusions.

In conclusion, the results suggest: a good awareness of training needs coaches on possible problems arising from the practice of rhythmic agonistic gymnastics; a lesser awareness of coaches about their educational, pedagogical and long-term health responsibilities; a difficulty of integration between sports companies and other institutions and actors involved in the educational process and the growth of young people.

These results provide relevant guidance for the planning of coach training plans. It is necessary to bridge the wide gaps in the pedagogical aspects. Confirming that the information and interest on the methodologies and contents attributable to the educational and pedagogical field are lacking in the trainers is the data collected on the knowledge of the Life Skills education model, virtually unknown to all respondents (only 1 in 98 coaches says she has heard of it). Regarding this aspect, it is important to emphasize that the Life Skills education model, as several authors claim, can be a valid method for improving sports performance as well as training these skills means improving self-esteem, decision-making skills, self-awareness, emotion management, and stress all aspects involved in successful sports performance and, above all, in positive youth development [22-24].
Another important aspect emerging from the study is the need to increase awareness of coaches about their educational, pedagogical and long-term health responsibilities, providing them a scientific support.

\section{References}

[1] Brenner, J. S. 2016. "Sports Specialization and Intensive Training in Young Athletes." Pediatrics 138 (3): e20162148.

[2] Coppola, S., Vastola, R., Scatigna, M., and Fabiani, L. 2015. "Training and Health in Gymnastics." Journal of Human Sport and Exercise 10 (1): S391-8.

[3] Georgopoulos, N. A., Markou, K. B., Theodoropoulou, A., Paraskevopoulou, P., Varki, L., Zazantzi, Z., Leglise, M., and Vagenakis, A. G. 1999. "Growth and Pubertal Development in Elite Female Rhythmic Gymnasts." J. Clin Endocrinol Metab 84 (12): 4525-30.

[4] Ávila-Carvalho, L., Klentrou, P., da Luz Palomero, M., and Lebre, E. 2013. "Anthropometric Profiles and Age at Menarche in Elite Group Rhythmic Gymnasts according to Their Chronological Age." Science \& Sports 28 (4): $172-80$.

[5] Theintz, GE, Howald, H, Weiss, U. \& Sizonenko, PC. Evidence of a reduction of growth potential in adolescent female Gymnasts. Journal of Pediatrics, 1993, 122; 306-313.

[6] Komanthi, K., Theodosis, E., and Apostolos, S. 2012. "Eating Disorders in the World of Sport: The Experiences of Rhythmic Gymnasts." Biology of Exercise 8 (2).

[7] De Oliveira, G. L., de Pinho Gonçalves, P. S., de Oliveira, T. A. P., Valentim Silva, J. R., Roquetti Fernandes, P., and Fernandes Filho, J. 2017. "Assessment of Body Composition, Somatotype and Eating Disorders in Rhythmic Gymnasts." Journal of Exercise Physiology Online 20 (1): 125-39.

[8] Czajkowska, M., Plinta, R., Rutkowska, M., Brzęk, A., Skrzypulec-Plinta, V., and Drosdzol-Cop, A. 2019. "Menstrual Cycle Disorders in Professional Female Rhythmic Gymnasts." International Journal of Environmental Research and Public Health 16 (8): 1470.

[9] Blake, T. E. 2015. "Relationship of Energy Balance and Body Composition in Elite Female Gymnasts."

[10] Center for Statistical Studies and Observatories for Sport. 2017. Monitoring CONI-FSN-DSA 2017, Coni (Italian National Olympic Committee) Foro Italico, 00135 Rome.

[11] Danish, S. J., Nellen, V. C., and Owens, S. S. 1996. "Teaching Life Skills through Sport: Community-Based Programs for Adolescents." In Exploring Sport and Exercise Psychology, edited by J. L. Van Raalte, \& B. Brewer. Washington, DC: American Psychological Association, pp. 205-25. 
[12] Jakson, N. H., Howes, F. S., Gupta, S., Doyle, J. L., and Waters, E. 2005. "Policy Interventions Implemented trough Sporting Organisations for Promoting Healthy Behaviour Change." The Cochrane Database of Systematic Reviews, Issue 2

[13] Dowling, F., Fitzgerald, H., and Flintoff, A. 2012. Equity and Difference in Physical Education, Youth Sport and Health: A Narrative Approach. Routledge.

[14] Dyson, B., Griffin, L. L., and Hastie, P. 2004. "Sport Education, Tactical Games, and Cooperative Learning: Theoretical and Pedagogical Considerations." Quest 56 (2): 226-40.

[15] Renshaw, I., Chow, J. Y., Davids, K., and Button, C. 2015. Nonlinear Pedagogy in Skill Acquisition: An Introduction. Routledge.

[16] Coppola, S., and Papa, S. 2015. "Physical Activity in the Developmental Age. Benefits Analysis and Assessment Tools." In L'attività fisica in età evolutiva. Lecce: Pensa Editor, 44-9.

[17] SINU (Italian Society of Human Nutrition). 2014. "Recommended Dietary Intakes for Energy and Nutrient for the Italian Population.” Accessed September 12, 2019 http://www.sinu.it/html/pag/tabelle_larn_2014_rev.asp.

[18] European Food Safety Authority, European Commission.
2009. "Food Supplements." Accessed October 2, 2019. http://www.efsa.europa.eu/en/topics/topic/food-suppleme nts.

[19] Angeli, A., Minetto, M., Dovio, A., and Paccotti, P. 2004. "The Overtraining Syndrome in Athletes: A Stress-Related Disorder." Journal of Endocrinological Investigation 27 (6): 603-12.

[20] Danish, S. J. (2002). Teaching life skills through sport. Paradoxes of youth and sport, 49-60.

[21] Petitpas, A. J., Van Raalte, J. L., Cornelius, A. E., and Presbrey, J. 2004. “A Life Skills Development Program for High School Student-Athletes." The Journal of Primary Prevention 24 (3): 325-34.

[22] Danish, S., Forneris, T., Hodge, K., and Heke, I. 2004. "Enhancing Youth Development through Sport." World Leisure Journal 46 (3): 38-49.

[23] Papacharisis, V., Goudas, M., Danish, S. J., and Theodorakis, Y. 2005. "The Effectiveness of Teaching a Life Skills Program in a Sport Context."Journal of Applied Sport Psychology 17 (3): 247-54.

[24] Gould, D., and Carson, S. 2008. "Life Skills Development through Sport: Current Status and Future Directions." International Review of Sport and Exercise Psychology 1 (1): 58-78. 